\title{
RESULTADOS DA COMISSÃO INTRA-HOSPITALAR DE DOAÇÃO DE ÓRGÃOS E TECIDOS PARA TRANSPLANTE (CIHDOTT) DO HOSPITAL CRISTO REDENTOR DE PORTO ALEGRE
}

\author{
Results from the Intra-Hospital Commission for Organ and Tissue Donation for Transplantation \\ (CIHDOTT) at Hospital Cristo Redentor in Porto Alegre
}

\author{
Sue Helen Barreto Marques', Paula De Cézaro', Danieli Cerri Soares², Nára Selaimen Gaertner de Azeredo³
}

\begin{abstract}
RESUMO
A doação de órgãos sempre foi um tema polêmico. Tão logo os transplantes se firmaram, seu maior fator limitante passou a ser a escassez de órgãos. A remoção de órgãos e tecidos só pode acontecer após o diagnóstico de morte encefálica, definido como a parada completa e irreversível das funções encefálicas. A fim de agilizar o processo de captação e doação de órgãos, foram instauradas as Comissões Intra-Hospitalares de Doação de Órgãos e Tecidos para Transplante (CIHDOTT) através da portaria no 1.262, de 16 de junho de 2006. O Hospital Cristo Redentor (HCR) é referência em trauma e neurologia, sendo um dos grandes captadores de órgãos do Rio Grande do Sul. Objetivo: O objetivo deste trabalho é apresentar os dados relativos à captação no HCR. Métodos: Os dados foram recuperados desde o ano 2005. Não há registros confirmados de captação nos anos anteriores. Resultados: No primeiro semestre de 2005, apenas 9,2\% dos pacientes que foram a óbito tiveram suas famílias abordadas quanto à doação. No segundo semestre foram 10,3\% das famílias abordadas, seguidos por 19,6\% e 39,1\% respectivamente no primeiro e segundo semestres de 2006. Em 2007, no primeiro período, 26,6\% das famílias foram abordadas pela CIHDOTT e 33,8\% no segundo semestre do mesmo ano. Conclusões: Nota-se com a implantação da CIHDOTT um aumento no número de famílias abordadas tanto na captação de córneas como na captação de múltiplos órgãos. Esse achado revela que apesar de estar ativa há pouco tempo, a CIHDOTT do HCR consegue atuar de forma significativa.
\end{abstract}

Descritores: Transplantes; Política de Saúde; Morte Encefálica

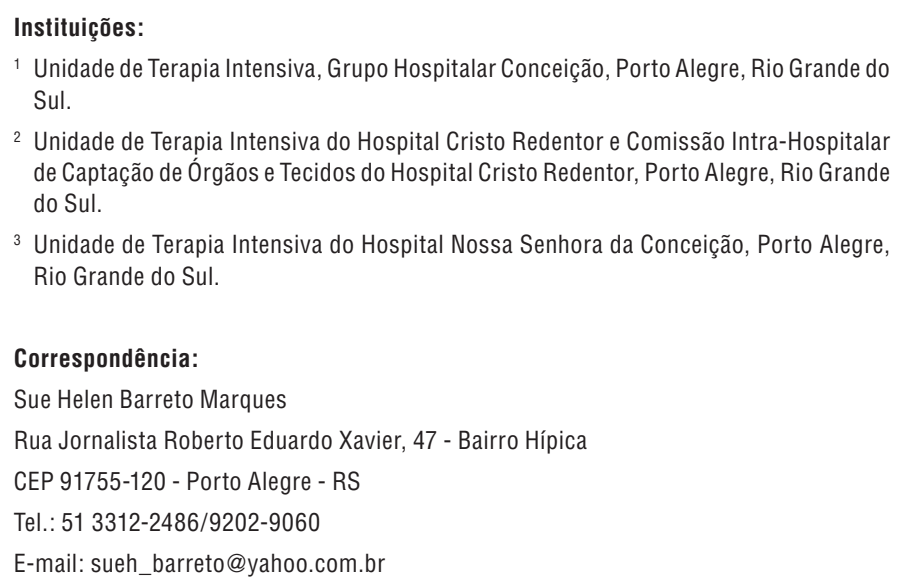

1 Unidade de Terapia Intensiva, Grupo Hospitalar Conceição, Porto Alegre, Rio Grande do Sul.

2 Unidade de Terapia Intensiva do Hospital Cristo Redentor e Comissão Intra-Hospitalar de Captação de Órgãos e Tecidos do Hospital Cristo Redentor, Porto Alegre, Rio Grande do Sul.

${ }^{3}$ Unidade de Terapia Intensiva do Hospital Nossa Senhora da Conceição, Porto Alegre, Rio Grande do Sul.

Correspondência:

Sue Helen Barreto Marques

Rua Jornalista Roberto Eduardo Xavier, 47 - Bairro Hípica

CEP 91755-120 - Porto Alegre - RS

Tel.: 51 3312-2486/9202-9060

E-mail: sueh_barreto@yahoo.com.br

Recebido em: 03.07.2007

Aceito em: 16.07.2007

\section{INTRODUÇÃO}

A doação de órgãos sempre foi um tema polêmico, que tem despertado interesse e discussões em várias comunidades, provocando debates entre opiniões divergentes. ${ }^{1,2}$ Há algumas décadas, a transferência de um órgão de uma pessoa para outra parecia ficção científica. Atualmente, o transplante é o tratamento de escolha para muitos pacientes. ${ }^{3}$ Porém, infelizmente, estamos nos confrontando com a realidade da falta de doação de órgãos e tecidos, o que aumenta cada vez mais a fila de espera, composta por pessoas que sofrem e vêem no transplante de órgãos sua única alternativa para continuar vivendo.

Tão logo os transplantes se firmaram como tratamento viável, seu maior limitante passou a ser a escassez de órgãos, que gera um grande desequilíbrio entre a oferta e a demanda. Aparentemente, o caminho mais promissor para aumentar a oferta de órgãos seria a otimização do uso de sua principal fonte: o doador falecido, que pode oferecer, simultaneamente, oito órgãos para transplantes, além das córneas, ossos e pele. ${ }^{4}$

Essa escassez pode ser atribuída tanto à desinformação da população quanto aos problemas estruturais do sistema de saúde. No panorama internacional aparecem questões que podem ser 
consideradas universais em relação à doação de órgãos, sendo a negativa familiar em consentir a doação citada como o principal entrave na efetivação do transplante. ${ }^{5}$

O dilema é intenso e cabe aos profissionais inseridos nesse processo absterem-se de qualquer julgamento, conduzindo a situação com sensibilidade e ética. Dois valores devem ser prioritariamente preservados: a vida e a dignidade do cadáver, pois esse não é um objeto e deve ser cercado de respeito. ${ }^{1}$

A remoção de órgãos e tecidos só poderá acontecer após o diagnóstico de morte encefálica, conforme resolução do Conselho Federal de Medicina, e a doação dependerá da autorização do cônjuge ou parente maior de idade, obedecida a linha sucessória reta ou colateral, até o segundo grau inclusive. ${ }^{6}$

Em estudo realizado com 18 famílias de doadores de órgãos, o conhecimento limitado das famílias acerca do conceito de morte encefálica mostra-se um elemento que dificulta a tomada de decisão. ${ }^{5} \mathrm{O}$ desconhecimento e a não aceitação da morte encefálica é compreensível, uma vez que, classicamente, a morte era definida como a cessação das funções cardíaca e respiratória. Para a manifestação do consentimento, é importante que os familiares tenham os esclarecimentos necessários sobre o processo de doação, incluindo o diagnóstico de morte encefálica?

Nos Estados Unidos, assim como no Brasil, a escassez de órgãos para transplante mostra-se uma frustrante realidade. Dois fatoreschave são responsáveis: primeiro, a dificuldade na detecção da morte encefálica, o que acaba inviabilizando a doação; segundo, a necessidade do consentimento da família do potencial doador, o que limita o número de transplantes. Em média, não mais que 50\% das famílias abordadas concordam com a doação. ${ }^{8}$

A morte encefálica (ME) é definida como parada completa e irreversível das funções encefálicas, impossibilitando a manutenção da vida sem o auxílio de meios artificiais. ${ }^{9}$ Apesar desse conceito já estar bem definido na comunidade científica mundial há pelo menos 30 anos, ele ainda não é bem aceito pela população em geral. ${ }^{10}$

No Brasil, o diagnóstico de morte encefálica é definido pela Resolução CFM no 1480/97. Inicialmente, é necessário certificarse que o paciente tenha identificação e registro hospitalar. A causa do coma irresponsivo deve ser conhecida e estabelecida. $\mathrm{O}$ paciente não pode estar hipotérmico (temperatura axilar $<35^{\circ} \mathrm{C}$ ), não pode estar recebendo drogas supressoras do Sistema Nervoso Central e nem estar em hipotensão arterial (a pressão arterial sistólica deve estar maior ou igual a 90 milímetros de mercúrio). Preenchidos esses itens, o paciente deve ser submetido a dois exames neurológicos, que devem ser realizados por dois médicos diferentes, não integrantes da equipe de remoção e transplante, para avaliar a integridade do tronco cerebral. O intervalo de tempo mínimo entre um exame e outro é de seis horas. Além dos dois testes clínicos, ressalta-se ainda a obrigatoriedade de um exame complementar para mostrar ausência de atividade elétrica cerebral ou de atividade metabólica cerebral ou de perfusão sangüínea cerebral. Esse exame será definido pelo médico e pode ser: Angiografia Cerebral, Cintilografia Radioisotópica, Doppler Transcraniano, Monitorização da pressão intracraniana, Tomografia computadorizada com xenônio, Tomografia por emissão de fóton único, EEG, Tomografia por emissão de positróns, Extração Cerebral de oxigênio, dentre outros. ${ }^{11}$

Essa normatização visa permitir a doação de órgãos, e, quando não for possível, o médico deve suspender o suporte vital desses pacientes considerados mortos, após a comunicação à família. No Brasil a comunicação de ME para as equipes de captação de órgãos é compulsória. ${ }^{12}$

No Brasil, havia uma tendência de crescimento constante no número de transplantes. Entre os anos de 1999 e 2004 obteve-se um crescimento de 3 doadores por milhão de população (pmp) para 7,4 doadores pmp. Se esse crescimento fosse mantido, em dez anos seriam alcançadas as taxas médias atuais dos países desenvolvidos (15 a 25 doadores pmp). Mas, em 2005 observou-se uma queda em relação a 2004 (de 7,3 para 6,3 doadores pmp) que continuou em 2006 com 6,0 doadores pmp. O primeiro semestre de 2007 seguiu a mesma tendência, com uma diminuição na taxa de doadores efetivos no país para 5,4 doadores pmp. A Associação Brasileira de Transplantes de Órgãos (ABTO) associa essa queda com o fato de não haver uma política estabelecida para os transplantes no país, pelas dificuldades com o programa informatizado do Ministério da Saúde, pela ausência de resolução para o emprego ou para a alocação de órgãos de doadores limítrofes, pela penalização para integrantes de equipes de transplante que são impedidos por portaria de atuar como coordenadores hospitalares de transplante, pelo nãocontrole das atividades e dos resultados dos centros de transplantes, pela desigualdade na distribuição dos centros de transplante nas diferentes regiões e pelas dificuldades no fornecimento das medicações imunossupressoras". 13,14,15

O Rio Grande do Sul (RS) tem mostrado uma estagnação na doação de órgãos nos últimos anos. Em 2004, apresentou 12,0 doadores pmp, com um aumento em 2005 para 13,2 doadores pmp. Em 2006 voltou para 12 doadores pmp, mantendo o mesmo valor em 2007. Hoje, mostra-se como o segundo estado brasileiro em doação de órgãos, ficando atrás apenas de Santa Catarina com 14,7 doadores pmp em 2007. ${ }^{13,14,15}$

Com a finalidade de agilizar o processo de captação e doação de órgãos, foram instauradas as Comissões Intra-Hospitalares de Doação de Órgãos e Tecidos para Transplante (CIHDOTT) através da portaria no 1.262 , de 16 de junho de 2006. As comissões devem ser compostas por no mínimo três membros de nível superior, dentre os quais um médico ou enfermeiro designado como coordenador. Dentre suas funções, está a articulação com a Central de Transplantes, notificando as situações de possíveis doações de órgãos e tecidos, a identificação dos recursos diagnósticos disponíveis na instituição, a garantia de uma adequada entrevista familiar para solicitação da doação e a disponibilização dos insumos necessários para a captação de órgãos e tecidos no hospital. É necessário que a CIHDOTT seja efetiva e integrada com os demais profissionais, capaz de agilizar todo o processo de captação para os potenciais doadores. ${ }^{16}$

Do ponto de vista institucional, cria-se o Sistema Nacional de Transplante (SNT), com o objetivo de desenvolver nacionalmente o processo de captação e distribuição de órgão e tecidos, sob a responsabilidade das três esferas de governo, formado pelas Centrais de Notificação, Captação e Distribuição de Órgãos (CNCDO). É obrigatório que todos os serviços de saúde notifiquem às CNCDO de seus Estados a ocorrência da morte encefálica. É também de responsabilidade dos serviços de saúde inscrever o potencial receptor no sistema de lista única, na CNCDO de sua área de residência, bem como fornecer as explicações específicas sobre os critérios de distribuição do órgão ou tecido ao qual se relaciona como possível receptor. ${ }^{6}$ 
O Hospital Cristo Redentor (HCR), situado na Zona Norte de Porto Alegre, é referência em trauma e neurologia, sendo um dos grandes captadores de órgãos do Rio Grande do Sul. Assim, o objetivo deste trabalho é apresentar os dados relativos à captação no HCR, considerando que a CIHDOTT foi implantada nesse hospital em junho de 2006.

\section{MÉTODOS}

Pesquisa documental retrospectiva. Os dados relativos à captação de órgãos no HCR foram recuperados desde o ano 2005. Não há registros confirmados de captações nos anos anteriores.

Será observado o rigor ético quanto à propriedade intelectual dos textos científicos pesquisados no que diz respeito ao uso do conteúdo e de citação das partes das obras consultadas. A preservação da identidade das pessoas será mantida e a divulgação das informações obtidas não acarretará prejuízos para os mesmos. A divulgação dos dados foi consentida pela Coordenação da Comissão IntraHospitalar de Captação de Órgãos e Tecidos do Hospital Cristo Redentor, Porto Alegre, Rio Grande do Sul.

\section{RESULTADOS}

No ano de 2005 ocorreram 563 óbitos no hospital, sendo que desses, 56 tiveram suas famílias abordadas quanto à doação, com a captação de 20 córneas e 10 múltiplos órgãos. Já em 2006, foram 552 óbitos, com 161 famílias abordadas, 38 córneas captadas e 10 múltiplos órgãos. Finalmente, em 2007, ocorreram 518 óbitos totais. A CIHDOTT abordou 157 famílias, garantindo a captação de 52 córneas e 18 múltiplos órgãos.

Assim, no primeiro semestre de 2005 apenas 9,2\% dos pacientes que foram a óbito no período tiveram suas famílias abordadas quanto à doação de órgãos e tecidos. No segundo semestre foram 10,3\% das famílias abordadas, seguidos por $19,6 \%$ e $39,1 \%$ respectivamente no primeiro e segundo semestre de 2006. Em 2007, no primeiro período, 26,6\% das famílias foram abordadas pela CIHDOTT e $33,8 \%$ no segundo semestre do mesmo ano.

\section{DISCUSSÃO}

A partir da criação da CIHDOTT em 2006, percebe-se uma significativa evolução na coleta de dados relativos à captação, como por exemplo sexo, idade, causas de óbito, causas da não doação, entre outros. Esses dados hoje já são registrados e organizados pela comissão. Segundo estatísticas da Comissão coletadas de outubro a dezembro de 2007 em relação à variável sexo do número total de potenciais doadores, identificou-se maior concentração do sexo masculino 34 (72,34\%) comparado ao sexo feminino $13(27,65 \%)$. Em relação à faixa etária, observou-se um paciente com menos de 10 anos, nove pacientes entre 10-30 anos, 13 pacientes entre 31-50 anos, 12 pacientes entre 51-70 anos, nove pacientes com mais de 70 anos e dois pacientes que não tiveram a idade identificada.

No gráfico abaixo destaca-se a tendência linear no número de famílias abordadas pela CIHDOTT no período de 2005 a 2007. Nota-se uma linha crescente no número de famílias entrevistadas. Apesar de não existir a CIHDOTT antes de junho de 2006, a captação de órgãos e tecidos ocorria na instituição de forma significativa. Porém, com a criação da Comissão, o processo de captação tornou-se fundamentado e baseado em protocolos, garantindo assim maior e constante efetividade.

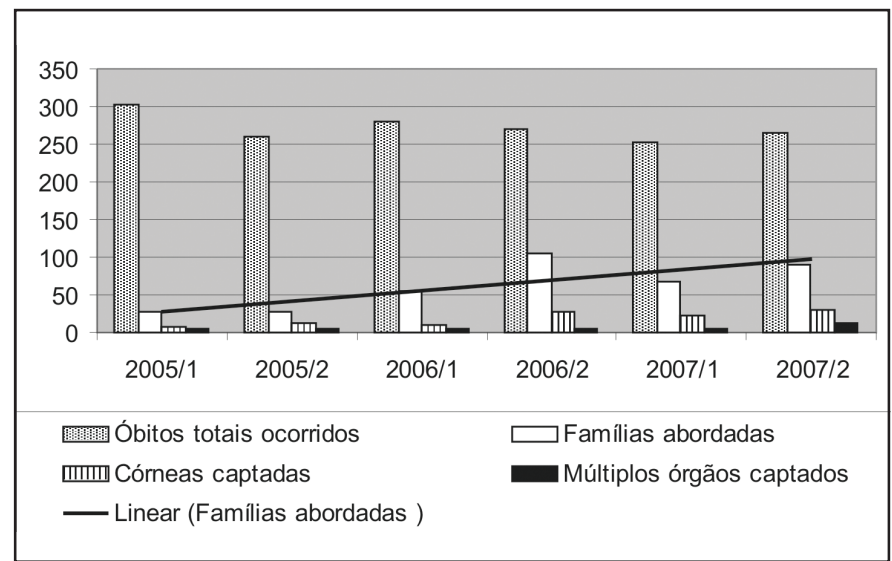

Evolução das atividades da CIHDOTT entre 2005 e 2007

\section{CONCLUSÕES}

Nota-se com a implantação da CIHDOTT, a partir do segundo semestre de 2006, um aumento significativo no número de famílias abordadas. Observa-se também um aumento importante na captação de córneas e um pouco mais sensível na captação de múltiplos órgãos, em especial no segundo semestre de 2007.

Esse achado revela que, apesar de estar ativa há pouco tempo, a CIHDOTT do referido hospital consegue atuar de forma significativa, apesar dos entraves burocráticos e institucionais. Espera-se que a Comissão possa se desenvolver mais nos próximos anos, aumentando o número de famílias abordadas e a retirada de múltiplos órgãos, tentando assim colaborar para a redução da escassez de órgãos e tecidos no país.

\section{ABSTRACT}

Organ donation has always been a controversial issue. When transplantation became steady, its higher limiting factor arose from the organ scarceness. The organs and tissues removal can only take place after the encephalic death diagnosis, defined as the complete and irreversible stop of encephalic functions. In order to speed up the organ procurement and donation process, Intra-Hospital Commissions for Organ and Tissue Donation for Transplant (CIHDOTT) have been established by the Decree no. 1.262 of June 16, 2006. Hospital Cristo Redentor (HCR), a reference in trauma and neurology has one of the biggest organ procurement organ rates in the state Rio Grande do Sul. Purposes: The purpose of this paper is to present data concerning the procurement at HCR. Methods: Data were collected since 2005. There is no confirmed registration evidencing procurement in previous years. Results: In the first semester of 2005, only $9.2 \%$ families of patients who died were approached to donate. During the second semester, $10.3 \%$ families were approached, followed by $19.6 \%$ and $39.1 \%$ in the first and second semester of 2006, respectively. In the first semester of 2007, 26.6\% families were approached by the CIHDOTT, and 
$33.8 \%$ in the second semester of that same year. Conclusions: From the CIHDOTT implantation, it is perceived an increase in the approach of families for the corneas and multiple organs procurement. Such finding discloses that despite its recent activity, the HCR CIHDOTT Commission performance is successful in a significant way.

Key Words: Transplantation; Health Policy; Brain Death.

\section{REFERÊNCIAS}

1. Lima EDRP, Magalhães MB, Nakamae DD. Aspectos Ético-Legais da Retirada e Transplantes de Tecidos, Órgãos e Partes do Corpo Humano. Rev latino-am enfermagem. 1997;5(4);5-12.

2. Moraes MW, Gallani MCBJ, Meneghin P. Crenças que Influenciam Adolescentes na Doação de Órgãos. Rev Esc Enferm USP. 2006;40(4):484-92.

3. Morgan V. Issues in Organ Donation and Transplantation. J R Soc Med. 1999; 92:356-358.

4. Rech TH, Rodrigues EMF. Manuseio do Potencial Doador de Múltiplos Órgãos Revista Brasileira de Terapia Intensiva. 2007:19:2:197-204.

5. Sadala MLA. A Experiência de Doar Órgãos na Visão de Familiares de Doadores. J Bras Nefrol. 2001;23(3):143-51.

6. Ribeiro CDM, Schramm FR. Atenção Médica, Transplante de Órgão e Tecidos e Política de Focalização. Cad Saúde Pública. 2006;22(9):1945-53.

7. Santos MJ, Massarollo MCKB. Processo de Doação de Órgãos: Percepção de Familiares de Doadores Cadáveres. Rev Latino-am Enfermagem. 2005 maio-junho; 13(3):382-7.

8. Nathan HM, Conrad SL, Held PJ, McCullough KP, Pietroski RE, Siminoff LA, et al. Organ Donation in the United States. Am J Transplant. 2003;3(4):29-40.

9. Kerridge IH, Saul P, Lowe M, McPhee J, Williams D. Death, Dying and Donation Organ Transplantation and the Diagnosis of Death. J Med Ethics. 2002 [cited 2007 oct 15];28;89-94. Available from: http://jme.bmj.com.
10. Bitencourt AGV, Neves FBCS, Durães L, Nascimento DT, Neves NMBC, Torreãos LA, et al. Avaliação do Conhecimento de Estudantes de Medicina sobre Morte Encefálica. Revista Brasileira de Terapia Intensiva. 2007:19:2:144-50

11. Conselho Federal de Medicina. Resolução CFM no 1.480/97. Disponível em: $<$ http://www.portalmedico.org.br/resolucoes/cfm/1997/1480 1997.htm>. [Acesso em 2007 nov 01]

12. Lago PM, Piva J, Garcia PC, Troster E, Bousso A, Sarno MO, et al. Brain Death: Medical Management in Seven Brazilian Pediatric Intensive Care Units. J Pediatr. 2007;83(2):133-140.

13. Associação Brasileira de Transplante de Órgãos. Registro Brasileiro de Transplantes. Ano XI. N. 2. Janeiro - dezembro 2005. Disponível em: < http://www.abto.org.br/ profissionais/profissionais.asp \#>. [Acesso em 2007 oct 30]

14. Associação Brasileira de Transplante de Órgãos. Registro Brasileiro de Transplantes. Ano XII. N. 2. Janeiro - dezembro 2006. Disponível em: < http://www.abto.org.br/ profissionais/profissionais.asp \#>. [Acesso em 2007 oct 30]

15. Associação Brasileira de Transplante de Órgãos. Registro Brasileiro de Transplantes. Ano XIII. N. 1. Janeiro - julho 2007. Disponível em: < http://www.abto.org.br/ profissionais/profissionais.asp \#>. [Acesso em 2007 oct 30]

16. Brasil. Ministério da Saúde. Portaria GM n ${ }^{\circ} 1.262$ de 16 de junho de 2006. Disponível em: $<\mathrm{http}: / / \mathrm{dtr} 2001$. saude.gov.br/transplantes/legislacao.htm>. [Acesso em 2007 oct 20] 